\title{
Investigating Student Attitudes Towards Using Hybrid MOOCs in the Higher Education of Saudi Arabia
}

\author{
Homoud Alanazi, Caroline Walker-Gleaves \\ Newcastle University \\ United Kingdom
}

\begin{abstract}
The phenomenon of Massive Open Online Courses (MOOCs) in higher education has not been examined thoroughly for Saudi Arabia. A significant question mark remains as to its success and response to it. The main purpose of this paper is to identify students' attitudes towards using Hybrid MOOCs with Flipped classrooms, as compared to traditional methods (face-to-face) during teaching the 'Educational Technology and Communication Skills' module. The research took place at Majmaah University for undergraduate students in the Faculty of Education in the first semester of the academic year 2017/2018. This research adopted a mixed-method approach comprising survey (quantitative approach) and semistructured interview (qualitative approach) tools. The results of the study indicate that students have positive attitudes toward using Hybrid MOOCs with Flipped Classrooms. In addition, student participants mention that Hybrid MOOCs with Flipped Classrooms have a strong potential in helping them learn according to their individual abilities, inside as well as outside the classroom. This research is one if the few of its kind ever done in Saudi Arabia, and contributes to filling a noticeable gap in the literature. In addition, the study's implications can be used for future policy making within the country's Ministry of Education.
\end{abstract}

\section{Introduction}

In recent years, many researchers have been studying how Massive Open Online Courses (MOOCs) can improve student academic achievement, experience, and attitudes in higher education within the context of formal education or distance learning. The phenomenon of Massive Open Online Courses was launched by faculty members at the University of Manitoba, Canada, namely George Siemens and Stephen Downes [1]. There are many explanations for the emergence of MOOCs. The starting philosophy was "Connectivism and Connective Knowledge". This is a novel idea in education pedagogy which describes the manner in which new learning opportunities have come into being from the widespread use of digital and web technologies and devices combined with the instructional paradigms of distributed and collaborative learning.

There are three types of MOOCs in educational contexts: cMOOCs, xMOOCs, and Hybrid MOOCs. The types mentioned are popular among educators and easy to understand in terms of MOOCs educational/theoretical origins and their pedagogy [2].

cMOOCs were the first types intended to test the values of connectivism by Siemens and his colleagues, as mentioned. They tried to understand and describe the nature of learning in networked contexts. Early cMOOCs were planned to support practices of creation, concepts of sharing, aggregation, and relations [3] between scattered clusters collaborating online. cMOOCs courses were intended to offer minimal centralized regulation and grow students' capabilities in order to offer insights to learn from the network.

In contrast, xMOOCs emerged to diverge from the cMOOCs offering more centralized, content driven, innovative, institutionally motivated courses on platforms such as edX (from which xMOOC gets its title), Udacity, and Coursera, not to mention being capable of offering LMS features. Wider media consideration and academic attention in MOOCs started in 2011 with "Introduction to Artificial Intelligence," a course given by Sebastian Thrun and Peter Norvig at Stanford University. This course registered over 160,000 applicants internationally and founded a more centralized, content-focused method to MOOCs [2].

Although the cMOOC-xMOOC binary makes it easier for scholars to distinguish between MOOCs, new literature diverts from this simplistic division towards more detailed and nuanced description of what happens in different types of MOOCs. Nowadays, Hybrid MOOCs, which are the third category, are an integration of processes, pedagogies, and elements of other MOOCs types, with the presence of a teacher to facilitate the learning activity.

The aim of a Hybrid MOOCs is to reach equilibrium between the affordances and weaknesses of XMOOCs and cMOOCs so that they can be used in more learner contexts, environments, and for a wider variety of activities.

A unique affordance of Hybrid MOOCs is that a balance of different instructional strategies could best help student development along a continuum of 
learning methods. Hybrid MOOCs can deliver helpful modes of learning in which students can get the experience and autonomy essential to attain academic accomplishments in more distributed and open learning environments. In short, Hybrid MOOCs can foster diversity in students, aid the progress of diversity in learning skills, as well as supporting engagement with emergent learning contexts and networked ones [2].

This study co-adopts Hybrid MOOCs alongside a flipped learning context, in order to first of all, offer a new teaching method for Majmaah University students, and secondly, change the learning pattern of students as they are usually passive learners with the teacher being the main source of their knowledge. Thirdly, this method gives the students an opportunity to study inside and outside the classroom. Fourthly, it offers the teacher much needed space to focus on difficulties students encountered on the platform while studying. Fifthly, this method allows the class time to be used much more efficiently. Sixthly, students are provided with more educational resources for their study.

The purpose of the study is to understand the students' outlooks towards the new teaching method in Majmaah University and investigate how they view technology entering education, after they have finished the 'Educational technology and Communication Skills module'. It is important to see whether they are satisfied with the new method or they still prefer the traditional face to face mode of learning. This question is important in regards to discerning how students' preconceptions changed after doing the course using educational technology. In short, the question that this study intends to ask is: What are the students' attitudes towards using Hybrid MOOCs in their education?

\section{Literature Review}

The literature review is classified into two parts for clarity:

\subsection{Student Attitudes towards Hybrid MOOCs}

When it comes to Hybrid MOOCs, there is a general consensus that students approve of this method of teaching. Fesol and Salam [4] discovered six categories regarding student perceptions towards Hybrid MOOCs within higher education. These six aspects are student beliefs towards web learning, study management, learning flexibility, technology usage, interaction on the internet, and learning within classrooms. When students are positively predisposed towards these six elements, they look favorably towards adapting to Hybrid MOOCs in education and vice versa. The study also found that the few students who have low self-independence in their studies, are more inclined to like traditional face to face pedagogy.

Kulik and Kidimova [5] conducted a study with findings which to the most part agree with the previous study discovering that $71 \%$ of the participants absolutely agree or agree that the inclusion of Hybrid MOOCs in their curriculum is a positive experience.

Joseph and Nath [6] conducted a study in India regarding the students' attitudes towards integrating MOOCs within Classrooms. They used a pre and post survey for data collection. The results of the presurvey indicate that $66 \%$ of the students do not plan to take MOOCs courses in their learning. However, in the post survey, their attitudes changed. The findings of post survey show that $60 \%$ of students indeed do plan to take up MOOCs courses in their education. In addition, $66 \%$ of students strongly propose that their university must implement MOOCs courses in the college campus.

Li et al. [7] conducted an experimental study involving 15 undergraduate students, one instructor, and two teaching assistants at the Zhejiang University in China regarding their perceptions towards integrated MOOCs with Flipped classrooms. Participants had a high level of satisfaction in several dimensions such as diversity in assessment, perceived ease of use, perceived usefulness, and Internet quality.

However, contrary to the previous studies where Hybrid MOOCs were very favored, a study done within the Russian education system intending to identify attitudes towards integrating MOOCs in Russian universities revealed that only top students, those who were active learners and highly autonomous, were positive towards this integration. Moreover, the study disclosed very clearly opinionated intentions of students regarding advantages and disadvantages of this new learning method [8].

Following the study in Russia, a research done in the USA also found that student perceptions on Hybrid MOOCs in higher education were not very positive. Students felt that there was a strong lack of alignment between the online component of the course and the face to face. In addition, they had much less inclination to participate in online discussion forum and preferred to do it in person [9].

\subsection{Student Attitudes towards Flipped Classrooms}

The Flipped learning classroom is a pedagogical approach in which the conventional model of classroom-based learning is turned on its head, so that students are introduced to the learning material before class, with classroom time then being used to deepen understanding through discussion with peers together with guided problem-solving activities, facilitated by the teacher. 
In terms of researching Flipped Classrooms, some have been focused on the school environment prior to higher education, while other scholars have been examining the influence of Flipped Classrooms in the higher education setting. In addition, these researchers have highlighted several critical subjects that are directly related to using Flipped Classrooms in education, such as academic achievement, motivation, satisfaction, and attitudes towards new teaching methods that feature the 'Flipped' elements.

When considering studies which have compared and contrasted student satisfaction at higher education, when exposed to Flipped and traditional classrooms, there is a general agreement that flipped classrooms are received better by students in terms of their fulfillment. Chen Hsieh, Wu and Marek [10] investigated the gains of the flipped classroom for students of English as a Foreign Language. The partakers were 48 English majors. Mixed methods were used (pre/post-tests, two questionnaires, teacher observation, and semi-structured focus-group interviews). The participants had high motivation, engagement, and satisfaction, confirming flipped classrooms usage being beneficial for EFL.

Hung [11] concurred with Chen Hsieh, Wu and Marek when the scholar explored the conceivable effects of using flipped classrooms for students of English language. A quasi-experimental design was employed, resulting in flipped classrooms being more effective than non-flipped classrooms in positively shaping the students' attitudes towards learning.

There were however some studies where student satisfaction, when exposed to Flipped classrooms, was slightly lower than traditional classrooms. The study done by Jensen, Kummer and Godoy [12] revealed that students had much more positive attitudes towards traditional classes. Their investigation was conducted in a large private university west of the United States. Students participating in this research were non-majors registered on an education biology course. The scholars employed a comparative quasi-experimental research design with two segments of the course being used in a test-control situation. 53 students participated in the non-flipped context and 55 students partook in the flipped context. The scholars made every endeavor to make sure there was group equivalence as much as possible.

An interesting study, on the other hand, disclosed that students had varying levels of satisfaction and different attitudes towards Flipped learning and were not uniform in their reception. Kim [13] probed students' thoughts using flipped classrooms in a university. The study had a quantitative and qualitative dimension. 123 students who registered in the flipped communication course were given questionnaires. Interviews were also given to a purposive sample of 15 students. The results were not consistent as students recounted better engagement and interaction with the flipped classroom, but lower motivation also incurred due to little familiarity with the new method. The final analysis revealed that students with different learning styles had very different levels of satisfaction and therefore, attitudes were different towards flipped classrooms.

\subsection{Combining Hybrid MOOCs and Flipped classrooms}

On the matter of merging Hybrid MOOCs with Flipped classrooms, it is necessary to first understand MOOC-based Hybrid initiatives. Kloos et al. [14] classified 6 types of hybrid pedagogies which combine MOOCs with traditional teaching methods (face-to-face) as follows: first of all, 'Local Digital Prelude' is a category where the initial segment of the course is entirely done on the MOOCs platform following up with a traditional face to face segment. Secondly, 'Flipping the Classroom' is when students study use MOOCs material online in their house every week; afterwards participating in lectures in order to strengthen their comprehension of the material they looked over. Thirdly, 'Canned digital teaching with f2f tutoring' comprises MOOCs material which students study for assessments in terms with no traditional classes while having the teachers present for enquiries in office hours. Fourthly, 'Canned digital teaching in $\mathrm{f} 2 \mathrm{f}$ course' is utilizing MOOCs materials as a textbook for traditional residential course. Fifthly, 'Remote tutoring in $\mathrm{f} 2 \mathrm{f}$ courses' encompasses digital interventions by specialists to accompany a traditional course. Finally, 'Canned digital teaching with remote tutoring', referring to fully online MOOCs courses supplemented with video-conferences for instructions.

Actually, flipping classroom and MOOCs are quite interconnected. MOOCs are the vehicle for transporting information for the classroom whereas flipped classrooms are a necessary accompaniment for MOOCs. Therefore, the two are harmonizing when used together and educationally beneficial. MOOCs are a thorough effective means for knowledge delivery. This is when flipped classrooms contribute to resolving various difficulties and challenges students face in the custom-made learning context.

MOOCs will inspire learners to have their own decisions based on their judgment and aspirations while Flipped classrooms are proficiently complementary for pupils in their study. This combination can enable students to manage their study time and completely respond to the requirements of diversification. The combination could enhance the tutor-learner rapport, and stimulate the pupils' resourcefulness and independence.

Although MOOCs bring with them sufficient online educational resources, good curriculum structure, alleviate backwardness of teaching 
materials/methods, help teachers' difficulties, improve students' attentiveness to technology, and assist students' with low learning capability, their weakness in classroom administration and teaching assessments makes it vital to use flipped classrooms to control, monitor, and appraise the teaching/learning impact [15].

\section{Research Methodology and Design}

This research has adopted a mixed-method approach, consisting of survey (quantitative approach) plus semi-structured interviews (qualitative approach). This approach offers a more comprehensive account of the topic under study compared to quantitative or qualitative approaches individually. In this study, descriptive statistics were utilized to describe the quantitative results, while thematic analysis has been used to analyze the qualitative findings.

The study has been conducted during 14 weeks in Majmaah University. The content of the Educational Technology and Communication Skills module was determined based on the main reference which is 'Educational Technology and Communication Skills', by Mamad Alqomaizy third edition, 2016. This book consists of fourteen chapters which the researcher and faculty members have selected ten chapters from. During the study, one chapter from the book was taught to students every week. The Rwag platform was used in order to upload course materials.

Personalized learning strategies are one of the important considerations which were taken into account when flipped classrooms were used together with Hybrid MOOCs. According to Wang et al. [16] and Liu, Wei and Gao [17], there are three stages to implementing Hybrid MOOCs with flipped classroom. The three phases are before classroom, in classroom, and after classroom and were used in the study as the graph shows:

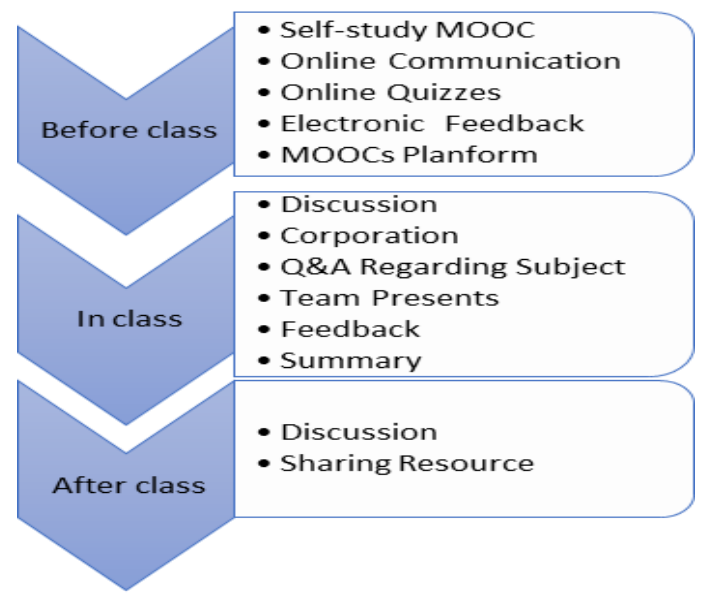

Figure 1: stages to implementing Hybrid MOOCs with flipped classroom

\subsection{Quantitative Sample Size}

The experimental group had 45 students. They attended class two hours each week from twelve o'clock to two o'clock. It must be noted that most students who participated in the study were full-time undergraduates from the three departments of Arabic Language, English Language, and Islamic Studies.

\subsection{Qualitative Sample Size}

In terms of the qualitative dimension of the study, 8 of the 45 students agreed to take part in the interview. The aim of the interview was to connect to these participants in order to explore and discover their attitudes towards using Hybrid MOOCs with Flipped Classrooms in more detail, comparing responses from the quantitative and qualitative aspects of the study.

\section{Results and Findings}

This section presents the findings from the quantitative and qualitative dimensions of the study:

\subsection{Quantitative Results}

The survey aims to understand students' attitudes towards their new method of learning. It consists of 15 items and students are asked to tick boxes pertaining to the Likert scale regarding each item of enquiry.

This is done using a 5-point scale where 5=Strongly Agree, 4=Agree, 3=Neutral, 2=Disagree, $1=$ Strongly Disagree. Therefore, the values closer to 5 indicate a higher agreement, while values closer to 1 indicate low agreement. Mean values ranging between 3.5 to 2.5 indicate moderate/medium agreement.

Table 1. Descriptive Analysis for Students' Attitudes towards Using Hybrid MOOCs with Flipped Classrooms

\begin{tabular}{|l|l|l|l|}
\hline Statements & $\mathbf{N}$ & Mean & $\begin{array}{c}\text { Std. } \\
\text { Deviati } \\
\text { on }\end{array}$ \\
\hline $\begin{array}{l}\text { 1.This method of } \\
\text { teaching gives me more } \\
\text { room to express myself. }\end{array}$ & 45 & 4.33 & 0.739 \\
\hline $\begin{array}{l}\text { 2.I would like other } \\
\text { subjects to be taught by } \\
\text { this method. }\end{array}$ & 45 & 4.11 & 0.714 \\
\hline $\begin{array}{l}\text { 3. Using this method of } \\
\text { teaching at university } \\
\text { level is very helpful. }\end{array}$ & 45 & 4.09 & 0.848 \\
\hline $\begin{array}{l}\text { 4. Using this method of } \\
\text { teaching contributes to }\end{array}$ & 45 & 4.09 & 0.821 \\
\hline
\end{tabular}




\begin{tabular}{|l|l|l|l|}
\hline $\begin{array}{l}\text { my personal } \\
\text { development. }\end{array}$ & & & \\
\hline $\begin{array}{l}\text { 5. This method of } \\
\text { teaching was interesting. }\end{array}$ & 45 & 4.11 & 0.885 \\
\hline $\begin{array}{l}\text { 6. This method of } \\
\text { teaching motivates me to } \\
\text { succeed. }\end{array}$ & 45 & 4.20 & 0.694 \\
\hline $\begin{array}{l}\text { 7. I would like to use this } \\
\text { method of teaching when } \\
\text { I become a teacher. }\end{array}$ & 45 & 4.07 & 0.821 \\
\hline $\begin{array}{l}\text { 8. I think this method } \\
\text { makes learning easy. }\end{array}$ & 45 & 4.44 & 0.624 \\
\hline $\begin{array}{l}\text { 9. I think using this } \\
\text { method is a positive idea. }\end{array}$ & 45 & 4.20 & 0.757 \\
\hline $\begin{array}{l}\text { 10. I would recommend } \\
\text { other students to use this } \\
\text { method in their studies. }\end{array}$ & 45 & 4.31 & 0.668 \\
\hline $\begin{array}{l}\text { 11. I enjoy learning from } \\
\text { the face to face } \\
\text { component of this } \\
\text { course. }\end{array}$ & 45 & 4.11 & 0.682 \\
\hline $\begin{array}{l}\text { 12. I enjoy learning from } \\
\text { the online component of } \\
\text { this course. }\end{array}$ & 45 & 4.18 & 0.684 \\
\hline $\begin{array}{l}\text { 13. I think working } \\
\text { within groups online is } \\
\text { really useful. }\end{array}$ & 45 & 4.24 & 0.773 \\
\hline $\begin{array}{l}\text { 14. I think working } \\
\text { within groups face to } \\
\text { face is really useful. }\end{array}$ & 45 & 4.33 & 0.716 \\
\hline $\begin{array}{l}\text { 15. I am satisfied in } \\
\text { using this method for my } \\
\text { learning. }\end{array}$ & 45 & 4.22 & 0.704 \\
\hline
\end{tabular}

As presented in Table1 the mean of the fifteen statements used to measure attitudes toward using Hybrids MOCCs with Flipped Classroom ranged between 4.44 to 4.07 , which indicate overall high agreement to attitudes toward using Hybrids MOCCs. Among the fifteen items used, the statement "I think this method makes learning easy" (Mean $=4.44, \mathrm{~S}$. $\mathrm{D}=0.624)$ and the statement "This method of teaching gives me more room to express myself" (Mean $=4.33$, $\mathrm{S} . \mathrm{D}=0.739)$ scored the highest average. While the lowest agreement was to statement "I would like to use this method of teaching when I become a teacher" (Mean=4.07, S.D=0. 821). In general, we conclude that all statements scored high agreement which reflect positive students toward using Hybrids were MOCCs.

\subsection{Qualitative Results}

The interview was aimed at obtaining student perspectives towards using Hybrid MOOCs with Flipped Classrooms, but on a deeper, more personal level.
At the beginning, students felt that they had difficulties in dealing with Hybrid MOOCs with Flipped Classrooms as it was their first educational experience with this new teaching method. Students perceived Hybrid MOOCs with Flipped Classrooms as difficult, a waste of time, and complicated at the beginning of the course. There was also tension and fear of failure among them when initially exposed to it. However, this perspective dramatically changed within the first few weeks. Students gained experience in dealing with Hybrid MOOCs with Flipped Classrooms which enabled them to acquire its benefits and advantages. Students found that Hybrid MOOCs with Flipped Classrooms eventually become enjoyable, easy, and have many benefits such as saving time and effort, not to mention added clarity when compared with traditional methods (face-toface).

Student 1 held that, "My views on the Hybrid MOOCs with Flipped Classrooms changed greatly. Before using it, I thought it is going to be tough and won't have benefit but after becoming used to it, I found learning easier". Moreover, Student 2 said, "I enjoyed learning and the clear objectives made my achievement great". Student 3 had severely shifted and changed his perception. Eventually he said, "I thought classes are going to be complicated but soon that changed. It fulfils my need and becomes very useful". Student 6 declared, "Before using Hybrid MOOCs, I had the fear of failure. It was an unknown experience but soon my views changed and quickly got used to it. Now it is my preferred learning method". After explaining changes in his perception, student 8 said, "I hope this method is applied for the rest of the courses. "Overall, although the survey element proved that there is a high agreement towards using Hybrid MOOCs with Flipped Classrooms, the interview elaborated further and showed that the students took time to get used to this method and their approval of it was not necessarily instantaneous.

\section{Discussion}

The results of quantitative and qualitative data collection methods suggest that students have a positive attitude toward using Hybrid MOOCs in their education. The implications of the findings are significant as not only do the findings of this study concur with previous research see [5],[6],[7], [18],[19] done on student attitudes towards MOOCs, this time the same type of general attitudes were given in a society known as being quite traditional see [20]. This is important in terms of MOOCs penetration in countries that are not yet considered fully developed. Another important issue was that preconceptions had a lot to do with student attitudes towards using MOOCs. Student preconceptions were not necessarily all positive, but with some experience with the new system, they changed and became optimistic see [13]. 
It was obvious that looking at the qualitative and quantitative findings, there is a sense of generalizability among students in terms of an overall belief in viability of this new method for other subjects see [21]. The multiple channels for learning (video, discussion, articles, quizzes...) had an influence on students' positive position towards MOOCs see [22]. In addition, the fact that they do not have to be physically present on campus was also received in a positive light. As Saudi Arabia is on the rise in terms of technology use among youth [23], the fact that students can use MOOCs on their mobile platforms has had a positive impact on their reception towards it. A prominent issue was that although it was the first time for all students studying with MOOCs, there was no negativity towards it, after they dealt with the new teaching method. In addition, the students who studied under this new method came from various departments who had to pass one common module and this diverse background did not in any way affect their positive perception of MOOCs. Moreover, contrary to the study done by Roshchina, Roshchin and Rudakov [8], students with different academic performance all liked MOOCs and it was not similar to their study where only high performing students liked it. Unlike the study done by Fesol and Salam [4] where preconceptions towards MOOCs remained the same after being exposed to it, as students who were predisposed towards traditional learning were more against MOOCs and students who were more predisposed towards flexible online learning were positive towards MOOCs, in this study, majority of students regardless of their predispositions towards online learning or traditional learning, became positive after a trying with it. The findings of this paper imply that pleasure see [24] in learning was a factor turning students' views towards MOOCs in a positive direction as the traditional learning in the country of Saudi Arabia is quite rigid see [20]. Novelty is another factor affecting student perceptions towards MOOCs to be positive, as for centuries, the strong man teacher position who had full control of the class was the head of educating students and now, his/her control is less with more autonomy for learners see [25], [26],[27].

The integration of Hybrid MOOCs with Flipped Classrooms in Majmaah University is still in its early stages of development. Although its reception was positive, still, time is needed to ensure that favourable attitudes towards this new pedagogy lead to sustained accommodating positions for more implementation of this method, as the current study only fixated on 45 students and one module. Since this is one of the very few studies assessing student attitudes towards Hybrid MOOCs with Flipped classrooms in Saudi Arabia, it is difficult to predict how and if this new method would be accepted in Saudi education system. However, this study gave an early positive indicator to what might come ahead and how students regard the new method in comparison to the face to face traditional teaching method which has been dominant for centuries in the kingdom.

\section{Conclusion}

The current paper successfully identified the responses, views, and reactions towards a new teaching method (Hybrid MOOCs with Flipped Classrooms) which was a move away from the traditional face to face pedagogy in Saudi Arabia. It used mixed methods (Interview plus survey) to discover their views. It appeared that although there is a general positive response towards using this new teaching method, this perception was not all favorable at the beginning as students needed time to adapt to it.

The current paper is the first study examining student attitudes towards using Hybrid MOOCs with Flipped Classrooms in higher education in the country of Saudi Arabia. Prior to it, to the authors' knowledge, no similar studies were conducted in the Middle East to obtain student views in this regard. As a result, the study presents novel and innovative research in this very important field of technological instruction.

\section{Acknowledgement}

I would like to thank the Saudi Government for giving me a scholarship and supporting me to complete my higher education in UK. Moreover, I would like to thank Dr Muge Satar Coen for her guidance and advice.

\section{References}

[1] Downes, Stephen. "Places to go: Connectivism \& connective knowledge." Innovate: Journal of Online Education 5, no. 1 (2008): 6.[2] Anders, Abram. "Theories and applications of massive online open courses (MOOCs): The case for hybrid design." The International Review of Research in Open and Distributed Learning 16, no. 6 (2015).

[3] Kop, Rita. "The challenges to connectivist learning on open online networks: Learning experiences during a massive open online course." The International Review of Research in Open and Distributed Learning 12, no. 3 (2011): 19-38.

[4] Fesol, Siti Feirsz Ahmad, and Sazilah Salam. "Towards MOOC for technical courses: A blended learning empirical analysis." In User Science and Engineering (i-USEr), 2016 4th International Conference on, pp. 116-121. IEEE, 2016.

[5] Kulik, Evgeniya, and Ksenia Kidimova. "Integrating MOOCs in University Curriculum: HSE University Experience." In EMOOCs-WIP, pp. 118-127. 2017.

[6] Joseph, AI Maria, and B. Asoke Nath. "Integration of Massive Open Online Education (MOOC) System with inClassroom Interaction and Assessment and Accreditation: An extensive report from a pilot study." In Proceedings of 
the international conference on e-learning, e-business, enterprise information systems, and e-Government (EEE), p. 105. The Steering Committee of The World Congress in Computer Science, Computer Engineering and Applied Computing (WorldComp), 2013.

[7] Li, Yan, Muhua Zhang, Curtis J. Bonk and Niki Guo. "Integrating MOOC and Flipped Classroom Practice in a Traditional Undergraduate Course: Students' Experience and Perceptions." iJET 10 (2015): 4-10.

[8] Roshchina, Y., S. Roshchin, and V. Rudakov. "The Demand for Massive Open Online Courses (MOOC): Evidence from Russian Education." Voprosy obrazovaniya/Educational Studies Moscow No 1, (2018): 174-199.

[9] Bruff, Derek O., Douglas H. Fisher, Kathryn E McEwen, and Blaine E. Smith. "Wrapping a MOOC: Student perceptions of an experiment in blended learning." Journal of Online Learning and Teaching 9, no. 2 (2013) 187.

[10] Chen Hsieh, Jun Scott, Wen-Chi Vivian Wu, and Michael W. Marek. "Using the flipped classroom to enhance EFL learning." Computer Assisted Language Learning 30, no. 1-2 (2017): 1-21.

[11] Hung, Hsiu-Ting. "Flipping the classroom for English language learners to foster active learning." Computer Assisted Language Learning 28, no. 1 (2015): 81-96.

[12] Jensen, Jamie L., Tyler A. Kummer, and Patricia D. D. M. Godoy. "Improvements from a flipped classroom may simply be the fruits of active learning." CBE-Life Sciences Education 14, no. 1 (2015): ar5.

[13] Kim, Jin-Young. "A study of students' perspectives on a flipped learning model and associations among personality, learning styles and satisfaction." Innovations in Education and Teaching International 55, no. 3 (2017): 314-324.

[14] Kloos, Carlos Delgado, Pedro J. Muñoz-Merino, Carlos Alario-Hoyos, Iria Estévez Ayres, and Carmen Fernández-Panadero. "Mixing and blending MOOC Technologies with face-to-face pedagogies." In 2015 IEEE Global Engineering Education Conference (EDUCON), pp. 967-971. IEEE, 2015.

[15] Li, Guangcai. "A Study on the Blended-Teaching Mode Combining MOOCs and Flipping Classroom in College English Teaching." In 7th International Conference on Education, Management, Information and Mechanical Engineering (EMIM 2017). Atlantis Press, 2017.

[16] Wang, Xin-Hong, Jing-Ping Wang, Fu-Ji Wen, Jun Wang, and Jian-Qing Tao. "Exploration and Practice of Blended Teaching Model Based Flipped Classroom and SPOC in Higher University." Journal of Education and Practice 7, no. 10 (2016): 99-104.
[17] Liu, Zhongwen, Li Wei, and Xia Gao. "A study on selfregulated micro-course learning and implicitly layered flipped classroom." Theory and Practice in Language Studies 6, no. 4 (2016): 870-877.

[18] Aharony, Noa, and Judit Bar-Ilan. "Students' perceptions on MOOCs: An exploratory study." Interdisciplinary Journal of e-Skills and Life Long Learning 12 (2016): 145-162.

[19] Holotescu, Carmen, Gabriela Grosseck, Vladimir CRETU, and Antoanela Naaji. "INTEGRATING MOOCs IN BLENDED COURSES." Elearning \& Software For Education 1 (2014).

[20] Elyas, Tariq, and Michelle Yvette Picard. "Teaching and moral tradition in Saudi Arabia: a paradigm of struggle or pathway towards globalization?" Procedia-Social and Behavioral Sciences 47 (2012): 1083-1086.

[21] Najafi, Hedieh, Carol Rolheiser, Stian Haklev, and Laurie Harrison. "Variations in Pedagogical Design of Massive Open Online Courses (MOOCs) Across Disciplines." Teaching \& Learning Inquiry 5, no. EPFLARTICLE-231224 (2017).

[22] Raposo-Rivas, M., E. Martinez-Figueira, and J. A. Sarmiento Campos. "A Study on the Pedagogical Components of MOOC." Comunicar Journal: MOOCs in Education 44 (2015).

[23] Baker, Razan. "Online social networks and Saudi youth participation in physical activity". Doctoral dissertation., Brunel University London, 2016.

[24] Davis, Hugh C., Kate Dickens, Manuel Leon Urrutia, Sanchéz Vera, Maria del Mar, and Su White. "MOOCs for Universities and Learners an analysis of motivating factors." (2014)

[25] Bingimlas, Khalid Abdullah. "Barriers to the successful integration of ICT in teaching and learning environments: A review of the literature." Eurasia journal of mathematics, science \& technology education 5, no. 3 (2009).

[26] Alkhatnai, Mubarak. "Learning styles of EFL Saudi college-level students in on-line and traditional educational environments." Doctoral dissertation, Indiana University of Pennsylvania (2011).

[27] Abedalla, Razak W., Jamie L. Pinchot, Najwa Samrgandi, and Rana Al-Masri. "Saudi Students' Perceptions of Online Education versus On-ground Education in Saudi Arabia." In Proceedings of the Information Systems Educators Conference ISSN, vol. 2167, p. 1435. 2014. 